\title{
UAV SURVEYING FOR A COMPLETE MAPPING AND DOCUMENTATION OF ARCHAEOLOGICAL FINDINGS. THE EARLY NEOLITHIC SITE OF PORTONOVO.
}

\author{
E.S. Malinverni ${ }^{\text {a* }}$, C. Conati Barbaro ${ }^{\text {b }}$, R. Pierdicca ${ }^{\text {c }}$, C.A. Bozzi ${ }^{\mathrm{a}}$, A.N. Tassetti ${ }^{\text {, }}$, \\ ${ }^{a}$ DICEA, Universitá Politecnica delle Marche, Via Brecce Bianche, Ancona, Italy - e.s.malinverni@univpm.it \\ ${ }^{\text {b }}$ Dipartimento di Scienze dell'Antichita, Sapienza Universita di Roma, Italy - cecilia.conati@ uniroma1.it \\ c DII, Universita Politecnica delle Marche, Via Brecce Bianche, Ancona - r.pierdicca@ univpm.it \\ ${ }^{\mathrm{d}}$ National Council of Researches, Institute of Marine Sciences (CNR-ISMAR), Ancona, Italy - nora.tassetti@an.ismar.cnr.it
}

Commission ThS11: Unmanned Aerial Systems: The Roadmap from Research to ApplicationsWG ICWG

KEY WORDS: Archaeology, Laser Scanner, Digital Dense Map, Close Range Photogrammetry, UAV, Excavation, 3D Documentation

\begin{abstract}
:
The huge potential of 3D digital acquisition techniques for the documentation of archaeological sites, as well as the related findings, is almost well established. In spite of the variety of available techniques, a sole documentation pipeline cannot be defined a priori because of the diversity of archaeological settings. Stratigraphic archaeological excavations, for example, require a systematic, quick and low cost 3D single-surface documentation because the nature of stratigraphic archaeology compels providing documentary evidence of any excavation phase. Only within a destructive process each single excavation cannot be identified, documented and interpreted and this implies the necessity of a re- examination of the work on field. In this context, this paper describes the methodology, carried out during the last years, to 3D document the Early Neolithic site of Portonovo (Ancona, Italy) and, in particular, its latest step consisting in a photogrammetric aerial survey by means of UAV platform. It completes the previous research delivered in the same site by means of terrestrial laser scanning and close range techniques and sets out different options for further reflection in terms of site coverage, resolution and campaign cost. With the support of a topographic network and a unique reference system, the full documentation of the site is managed in order to detail each excavation phase; besides, the final output proves how the 3D digital methodology can be completely integrated with reasonable costs during the excavation and used to interpret the archaeological context. Further contribution of this work is the comparison between several acquisition techniques (i.e. terrestrial and aerial), which could be useful as decision support system for different archaeological scenarios. The main objectives of the comparison are: i) the evaluation of 3D mapping accuracy from different data sources, ii) the definition of a standard pipeline for different archaeological needs and iii) the provision of different level of detail according to the user needs.
\end{abstract}

\section{INTRODUCTION}

In the Cultural Heritage domain, the wide spectrum of methodologies and instruments is particularly varied, ranging from the direct survey to complex and sophisticated data acquisition methods. Among others, the most widely adopted method are Terrestrial Laser Scanner (TLS) and digital photogrammetry, from the ground (with close range approaches) and with aerial platforms (RPAS). Even the aforementioned techniques are sufficient to provide themselves good results in terms of completeness and accuracy of the survey, the best approach is the multi-resolution one, by performing an integration of data arising from different sources (Balletti et al., 2015). Thanks to the integration of different type of acquisition technologies (i.e. image-based, active sensor based and UAV system) it is possible to convey a wider set of outcomes, suitable for different purposes, thanks to different restitution scales. This is particularly true for archaeological settings, a particular research context where investigation is mainly based on analysis, connection and interpretation of data collected during the excavation process. First and foremost, excavations are unrepeatable experiments where all the information, once identified, are recorded and removed from their original context and the main contribution of survey tools is to cope with the diachronic evolution of the site during the different ages (Dellepiane et al., 2013). Furthermore, the excavation process is spread over a long span of time, making more difficult the management of datasets dating back to different periods.

*Corresponding author
In this context, this paper describes the methodology, carried out during the last years, to 3D document the Early Neolithic site of Portonovo (Ancona, Italy) and, in particular, its latest step consisting in a photogrammetric aerial survey by means of UAV platform. It completes the previous research, (Barbaro, 2013) delivered in the same site by means of terrestrial laser scanning and close range photogrammetry techniques and sets out different options for further reflection in terms of site coverage, resolution and campaign cost. What are the advantages of the $3 \mathrm{D}$ digital acquisition techniques in this archaeological context? On the field it is possible to greatly reduce the time of the excavation mapping compared to conventional methods. These techniques also reduce the data acquisition errors, that can be biased by subjectivity. It is worth to remember that, in this particular case, at the end of each field campaign the excavation area is covered with earth and in the following season a new sector is explored. Therefore we do not have the possibility to leave open the whole area under investigation. The 3D digital acquisition techniques provides an opportunity to us to have at disposal a general overview of the field documentation, with photo mosaics and 3D representations, from the beginning of the excavation to the last campaign. By means of close range image and range based techniques, we can go into details, from the whole excavation area to the single structure; furthermore, we can analyse the topographical relationships between structures both vertically and horizontally and compare every time the metric values of the different structures. Thanks to Unmanned Aerial Vehicles (UAVs), a relative new tool in the field of archaeology, the knowledge of the site is strongly increased, since they allow to obtain a complete vision of the excavations 
over the years. The purpose of this study is to illuminate the potentials and downsides of using UAV's in archaeology, evaluating the exploitation of useful outputs like ortophotos and photomosaic. Finally, having a complete digital 3D mapping of the archaeological site, together with the 3D models of the structures, will help us to make visible and accessible to the general public this unique and peculiar site; given the fragility of the ovens and the strong erosion acting on the slope, it is not possible to turn them into an open air museum, but they can be spread to the wide public through virtual reconstructions.

\section{RELATED WORKS}

When dealing with Geomatics techniques for the survey of archaeological excavation, methods and approaches are chosen according to several pre-defined condition: typology of the excavation, morphology of the site, budget, equipment transportation issue and many more. Archaeological documentation should be the most effective, least destructive, most efficient and economical means of obtaining the needed information (Sulaiman et al., 2013). However, the need of combining multiple techniques depends on the fact that, nowadays, every single technique is not capable of giving good results for all the expected outputs. Consequently, as demonstrated by several works, the integration of techniques (integrated digital survey) represents the most suitable approach for the documentation of ancient findings, confirming its main role in the documentation and comprehension of excavation contexts. For the requalification of historical areas, the multi-range approach described in (Chiarini et al., 2014) proved the applicability and the efficiency of this techniques for different representation scale and type of subject. Besides, the integration of multi resolution data allows the generation of reality-based 3D models at different scales and levels of details, from the general overview until the detailed representation of objects and artefacts. The advantage is twofold: providing insiders with an instrument to control the complex conservation of the site and spread the knowledge of cultural goods to the common public (Guidi et al., 2008). The destructive nature of archaeological excavations and the spatial character of archaeological findings make 3D models valuable contributions to the documentation of archaeological information (Lonneville et al., 2014). With the increasing performances of aerial platform, the mapping of archaeological site is entrusted with the use of UAVs (Uribe et al., 2015). They actually represent the most powerful monitoring system to provide the necessary information to the archaeologists day by day. Therefore, they bring several advantages. The network of control points, usually present at each archaeological site, is generally used for orienting a photogrammetric bundle block image adjustment coming from an UAV platform. And more, the navigation control system is able to drive the aircraft following a pre-planned flight scheme (Rinaudo et al., 2012). Datasets derived can be used to generate accurate orthophotos, digital terrain models (DTMs) and can generate a variety of datasets that can be used to document and identify archaeological areas (Themistocleous et al., 2014). An accurate report of outputs and advantages for archaeology purposes can be found in (Nilsson, 2013). Actually, the pipeline of work from acquisition to the phase is well-established (Nilsson, 2013). In this light, we report our pipeline to achieve the full documentation of the site, in order to detail each excavation's phase; besides, the final output proves how the 3D digital methodology can be completely integrated with reasonable costs during the excavation and used to interpret the archaeological context.

\section{THE STUDY CASE}

The ancient Neolithic site of Portonovo Fosso Fontanaccia is located on the Conero promontory, along the Adriatic coast of Marche (Ancona, Italy), shown in Figure 1. This site represents a unique example of its kind in Italy (Conati Barbaro et al., 2013).

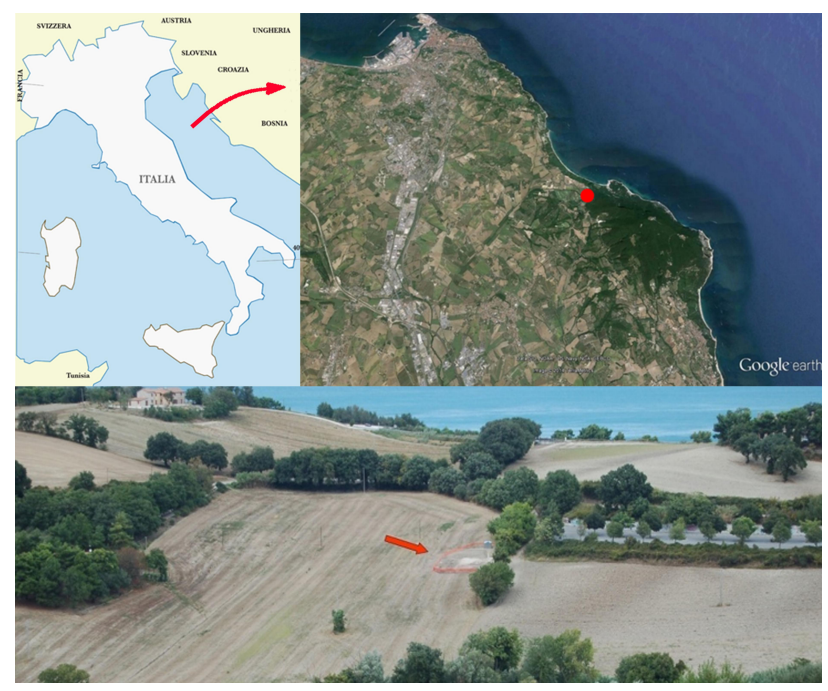

Figure 1: Localization of the site

It was first identified in the 1990s; since then, several excavation campaigns have brought to light a total of 23 underground ovens over an area of about $600^{2}$. The ovens were built by digging small cavities into the colluvial layer at different heights along a hill slope. Depending on the degree of erosion the recovered structures are both negative and only partially in elevation. Almost all of them overlook shallow and irregular depressions, which were dug to facilitate their excavation and to provide their access for use. These pits would have been quite deep: as an example, one of them was $0.90 \mathrm{~m}$ deep and $5 \mathrm{~m} x 4,20 \mathrm{~m}$ wide. Seven of the ovens, located lower on a slope, were entirely preserved because they were protected by a thicker superficial deposit. All the ovens located higher on the slope were instead very badly damaged by natural erosion and ploughing (see Figure 2 for details).

Despite their different states of preservation, all ovens share similar features and dimensions: the base is circular, flat, with diameters from 1,50 to $2,00 \mathrm{~m}$; the vaults are very low so that the maximum height does not exceed $50 \mathrm{~cm}$; there is only one central opening that is on average $0.50 \mathrm{~m}$ in width and $0.35 \mathrm{~m}$ in height. The inner lining is made by firing of the natural sediment. The floors were smoothed and in some cases covered with a light coating of clay. The PXRD analysis (X-ray powder diffraction) of hardened sediment samples of the inner walls of the ovens showed that the sediments were affected by exposure to very low temperatures not exceeding $500^{\circ} \mathrm{C}$. According to these data the temperature reached inside the ovens is considered too low for pottery firing, but is compatible with other uses such as cooking and food processing. Many charred barley caryopses and cereal grains were found, proving the hypothesis that the ovens were used for roasting cereals. Some flint artefacts show signs of thermal treatment. We can therefore assume that the heat of the ovens could also be used to improve the efficiency of the raw material for pressure flaking. According to the last absolute dating obtained so far the site was occupied over a long period from 5800 to $5400 \mathrm{BC}$ cal., but not all of the ovens were in use at the same moment (Conati Barbaro and Celant, Rome 5-9 October 2015). Each oven was probably made and used for a 

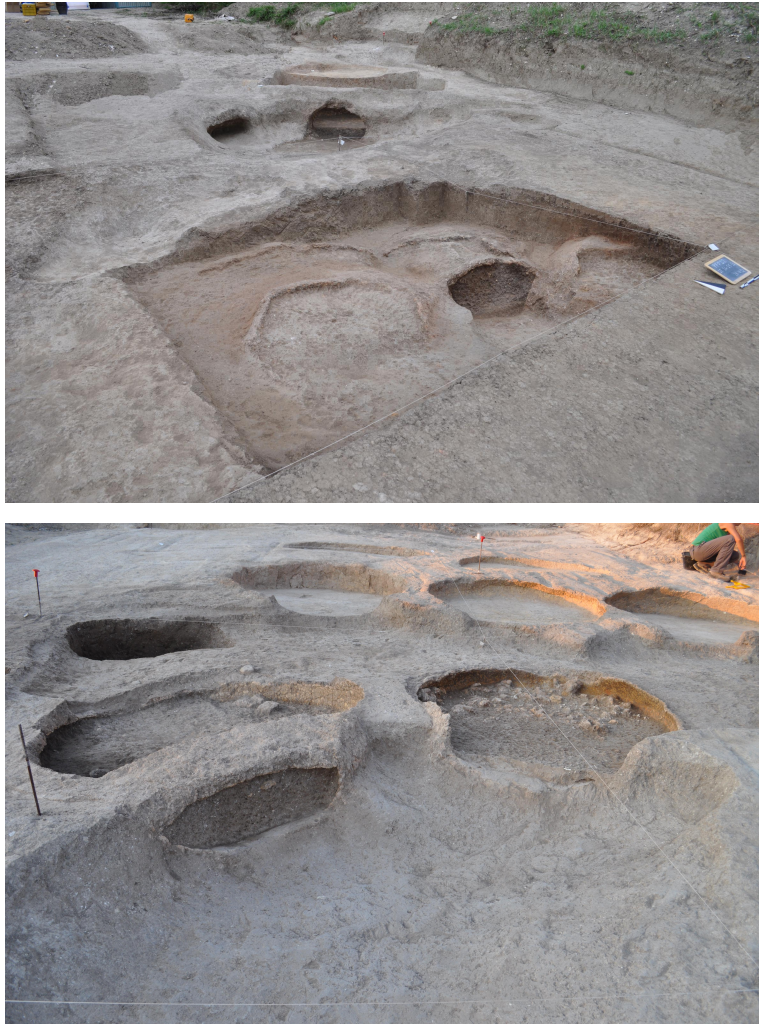

Figure 2: Archival images representing the historical evidence of the ruins, at the times of their discovery. The images show the condition of the ovens

few years and then abandoned, as there is no evidence of maintenance to extend its functional life. Three badly preserved burials were found within two ovens, containing the remains of two individuals and one adult male. This evidence clearly indicates the abandonment of the primary function of the ovens. To date we have not found any trace of a settlement connected to this site which could definitely be considered as a "specialized" production area.

Given the peculiarities of these structures it is a good case study for the application of 3D digital acquisition techniques. Therefore all of these structures require different types of documentation.

\section{METHODOLOGY}

After its discovery, dated back to the end of the nineties, soundings were conducted in 1999 and 2006 by the Superintendence for the Archaeological Heritage of Marche. Table 1 summarizes, by excavation year, the archaeological dataset from diverse sources in terms of data acquisition method, instrumental details and investigation extent.

\subsection{History of the excavations}

A local grid system of $4 \mathrm{~m} \times 4 \mathrm{~m}$ was set up in 2006, using the $\mathrm{X}$-axis as main reference system. This grid gradually enlarged over the years, according to the expansion of the excavation area. Since September 2011 systematic excavation campaigns have been undertaken by the Sapienza University of Rome over an area of about $600 \mathrm{~m}^{2}$, and later over an adjacent areas of $50 \mathrm{~m}^{2}$, recording manly by hand drawn documents/maps and daily field reports to register all the relevant observations and data interpretation during the workday. Archaeological materials (lithics, pottery, faunal and botanical remains) were recorded together with their position (in the local grid reference system), depth and Stratigraphic Unit (SU). Artefacts were removed, stored in numbered collections and marked in detailed plans (scale 1:10), in order to help the identification of possible associations and refitting during post-dig study. Each structure was recorded by field finds labels, detailed plans (scale 1:10) and sections (scale 1:20) to study morphology, depth articulation and relate the structures along the hillside in a general plan (scale 1:50). Each SU was documented by taking photographs and reports at various stages of excavation (at the beginning, when the SU is recognized, while being excavated and finally when it is completely dug) and organizing them by a computerized database storing Italian context sheets (SU reports) and rebuilding stratigraphic sequences.

An experience of low-height aerial photogrammetry was carried out in 2011 by a balloon-kites system equipped with a non-metrical camera with the aim of recording for the first time geometrical information of the archaeological site (Figure 3).
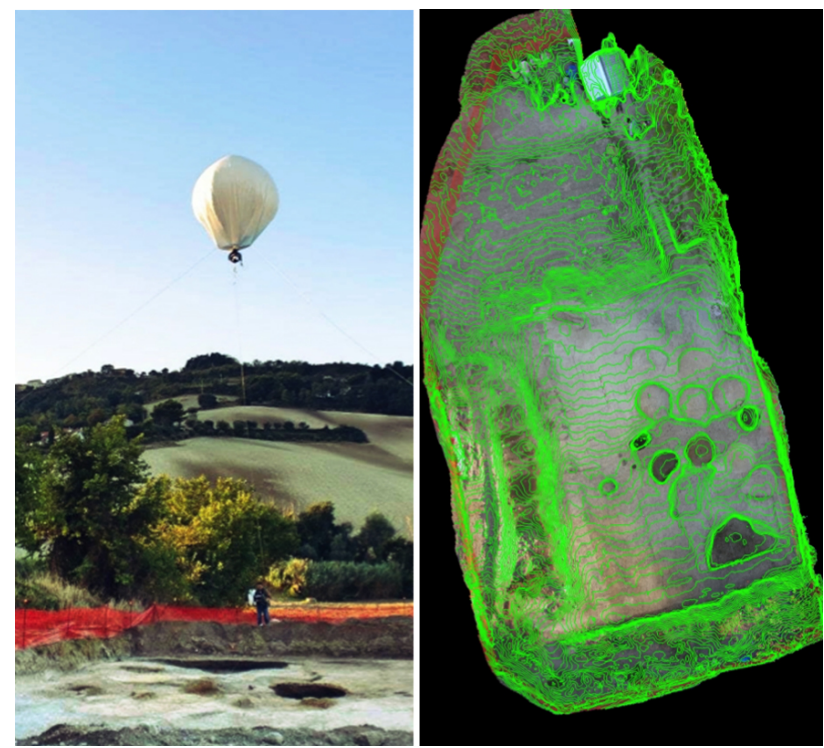

Figure 3: Acquisition of images by the balloon system and following georeferenced orthoimage with contours line on the top (excavation campaign 2011)

In a typical archaeological scenario like the one in Portonovo, structures and materials are scattered along the hill; hence, there was the necessity to create a topographic network to define a homogenous reference system, making possible the orientation of the acquired data as a whole inside a common reference system, for the future acquisitions. Moreover, these early fieldwork seasons revealed detailed stratigraphic sequences requiring a complex documentation and highlighting the need for a systematic and complete data acquisition planning, able to collect all the stratigraphic, topographic and cartographic data for the whole archaeological site.

For the aforementioned reasons, starting from 2013, an absolute reference system (GaussBoaga/Roma 1940 and geodetics heights) was created using a GNSS receiver (Topcon GRS-1) in VRS ${ }^{1}$ mode and used to orient the previous local $4 \mathrm{~m} \times 4 \mathrm{~m}$ grid system and each subsequent scattered survey. Furthermore, different survey methodologies such as Close Range Photogrammetry (CRP) and Terrestrial Laser Scanner (TLS) were tested and integrated in the ongoing documentation plan with the awareness

\footnotetext{
${ }^{1}$ Virtual Reference Station through the NETGEO network of permanent stations
} 
Table 1: List of archaeological datasets by excavation year

\begin{tabular}{|c|c|c|c|}
\hline Year & Acquisition methods & Instrumental details & Extent \\
\hline 1999 & Hand data documentary during trial soundings & & Localized sites \\
\hline 2006 & Hand data documentary during trial soundings & & Localized sites \\
\hline 2011 & $\begin{array}{l}\text { Hand data documentary } \\
\text { Aerostatic balloon for nadir/oblique image }\end{array}$ & & $\begin{array}{l}\text { Localized sites } \\
\text { Whole excavation }\left(194 \mathrm{~m}^{2}\right)\end{array}$ \\
\hline 2012 & Hand data documentary & & Localized sites \\
\hline 2013 & $\begin{array}{l}\text { Data documentary } \\
\text { 3D Laser scanner acquisitions } \\
\text { Terrestrial image acquisition (RGB) } \\
\text { Absolute reference system definition } \\
\text { (GaussBoaga/ Roma 1940) by GPS }\end{array}$ & $\begin{array}{l}- \\
\text { Faro Focus 3D } \\
\text { Sony A77 } \\
\text { Topcon GRS-1 } \\
\text { Topcon GPT-7005i }\end{array}$ & $\begin{array}{l}\text { Localized sites } \\
\text { Whole excavation }\left(47 \mathrm{~m}^{2}\right) \\
\text { Whole site } \\
\text { and outskirts }\left(300 \mathrm{~m}^{2}\right)\end{array}$ \\
\hline 2014 & $\begin{array}{l}\text { Data documentary } \\
\text { 3D Laser scanner acquisitions } \\
\text { Terrestrial image acquisition } \\
\text { UAV acquisition (RGB) }\end{array}$ & $\begin{array}{l}- \\
\text { Faro Focus 3D } \\
\text { Sony A77 } \\
\text { Canon powershot SX280 HS } \\
\text { Topcon GRS-1/Topcon GPT-7005i }\end{array}$ & $\begin{array}{l}\text { Localized spots } \\
\text { Whole excavation }\left(184 \mathrm{~m}^{2}\right) \\
\text { Whole site and outskirts } \\
\text { Whole site and outskirts }\end{array}$ \\
\hline 2015 & $\begin{array}{l}\text { Data documentary } \\
\text { 3D Laser scanner acquisitions } \\
\text { Terrestrial image acquisition (RGB+NIR) } \\
\text { UAV acquisition (RGB) } \\
\text { UAV acquisition (RGB+NIR) } \\
\text { Absolute target positioning by GPS/Total station }\end{array}$ & $\begin{array}{l}- \\
\text { Faro Focus 3D } \\
\text { Sony A77 } \\
\text { Canon S100, flight altitude of } 25 \mathrm{~m} \\
\text { Canon S100-RGBD+NIR } \\
\text { flight altitude 20m } \\
\text { Topcon GRS-1/Topcon GPT-7005i }\end{array}$ & $\begin{array}{l}\text { Localized spots } \\
\text { Whole excavation }\left(82 \mathrm{~m}^{2}\right) \\
\text { Whole site and outskirts extended } \\
\text { Whole site and outskirts } \\
\text { Whole site and outskirts }\end{array}$ \\
\hline
\end{tabular}

to increase the representative efficacy of the final representations and reach different geometric level of detail (LoD) of the archaeological scene. In particular, because ideally-suited (confined, standing with no presence of grass etc.), TLS and CRP data were both collected for the entire archaeological excavation $\left(300 \mathrm{~m}^{2}\right)$ with the first aim of a scientific comparison/accuracy assessment and then of a combined processing: total station's ground control points (GCPs) were used to drive the CRP orientation/bundle adjustment, while, to improve the final metric representation, the TLS mesh was used as base to wrap over the CRP texture. The results were quite complete, with high quality texture and georeferenced in the system of coordinates identified with the VRS survey in 2013. The generated 3D photorealistic model fulfilled metric and visualization purposes (Figure 4) and was useful to engage the public and assist archaeologists in their interpretations. In 2014, an UAV-based documentation was carried out and im-

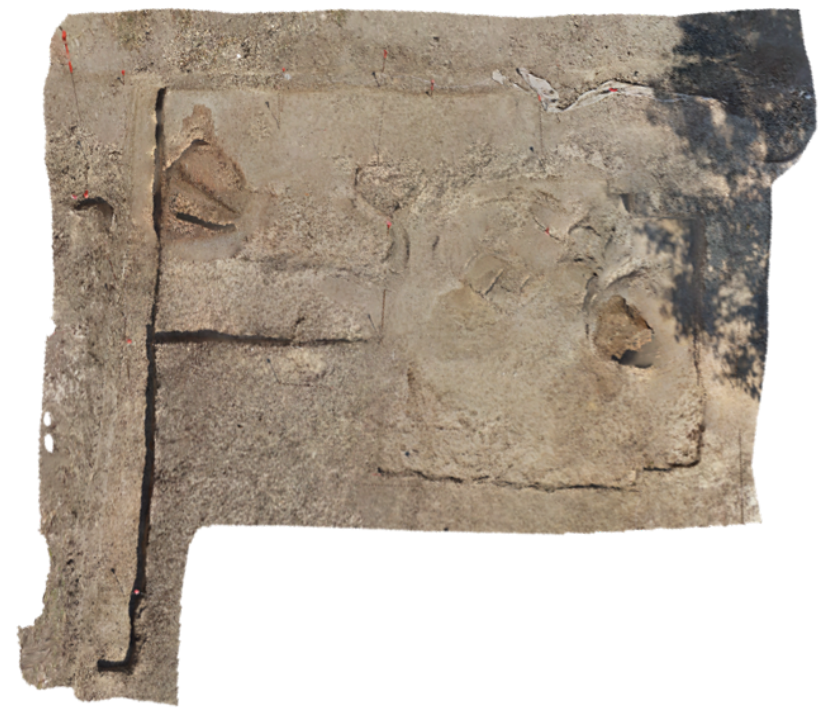

Figure 4: elevation model by CRP and TLS surveying (excavation campaign 2013) proved in 2015 with the joint acquisition of colour and NIR images. Since the absolute reference system set up in 2013, the aim has been to systematize all the procedures and technologies adopted for the documentation and handle datum issues related to the merger of data from different sources. The detail of the completion of the survey thanks to the adoption of UAV is detailed in the following section, while for a clear of the surveyed areas during the years refer to 5 .

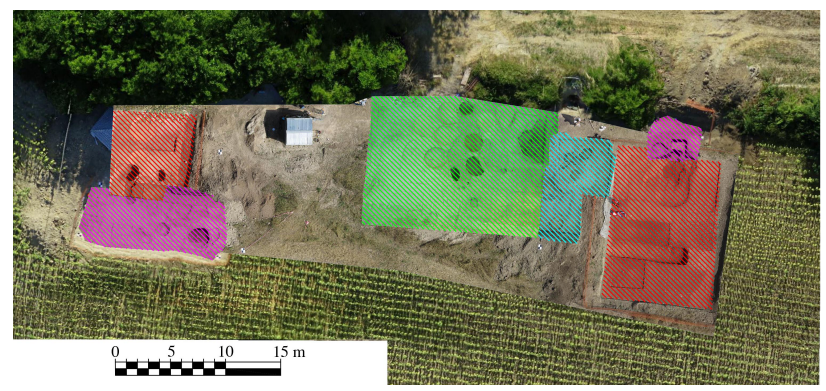

Figure 5: Survey areas by year: 2011-Green; 2013-Cyan; 2014Red; 2015-Violet

\subsection{Integration with UAV survey}

Beside carrying out TLS and CRP surveys, the documentation workflow was enriched with UAV photographic acquisitions of the whole archaeological site in two subsequent years (2014 and 2015). To reduce the payload a Canon power shot SX280HO, with a resolution of 12.Mpix, was mounted on an IRIS 3DR UAV system. Other features of the camera are the geotagging (through GPS and Wi-Fi) and the HS System to ensure good results also with limited illumination conditions. As usual, the flights were planned considering the site typology and the UAV platform constrains. Data were captured with two different elevations (about 20 and 60 meters) with a redundant amount of images to cover the entire area. This choice allowed to complete the previous work, with the aim of obtaining the whole site in a unique reference system and in a unique graphical outcome: the overall orthophoto with a high resolution, allowing the integration of of all 
the surveys performed before during different excavation years. To reach an accurate metric merging, the best solution would be to acquire nadiral and oblique views. However, due to the low cost of the equipment chosen for this work, we envisaged the adoption of pseudo-nadiral structures of view. This was sufficient to obtain the correct correspondence with the data acquired on the ground with both TLS and CRP and to avoid the presence of shadows. For each excavation area, we performed different flight sessions, using the photo's schemes that better fitted with the morphology of the site. Consequently, in the phase of data processing, we selected the photograms useful for the creation of the different elaborations.

Ground Control Points (GCPs), identified with "markers" scattered across the entire archaeological area, were measured by GPS and manually identified in Agisoft Photoscan in order to perform the bundle adjustment and the orientation of the entire UAV model in the absolute geo-reference system. Photoscan computes the orthophoto for each individual set of images; assembling them all at once it is not possible due to the high resolution, so that we segmented them into six pictures, and assembled them into a unique ortophoto of the site's, as described in Section 5. Figure 6 shows the area object of this set of survey with the related results.
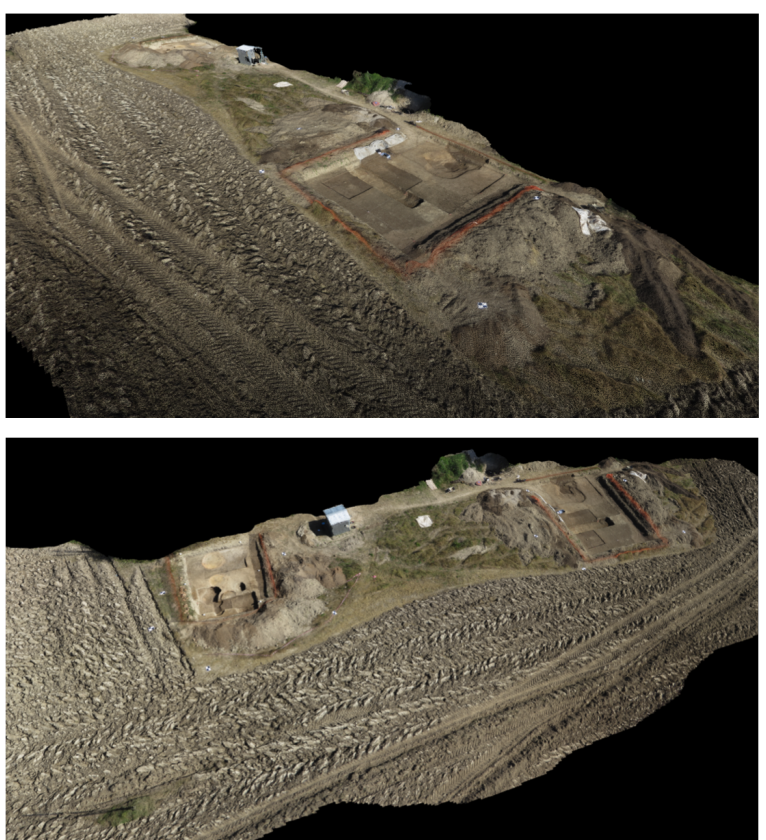

Figure 6: The area recorded during the excavation session in 2014. Filtered dense point cloud from UAV survey.

After the geo-referencing of the meshes and the optimization of the UAV model (i.e. outliers removal, simplification, cap-hole procedure etc.) it was possible to create a photo-mosaic and overlay it with simultaneous CRP and TLS surveys (excavation campaign 205) and later with all the previous ones. Once the survey was finished and the excavation work by the archaeologist team ended, the site was completely covered and gave back to the owners for farming purposes. In the following year, in 2015, the same other adjacent areas were excavated, and looking at the good results obtained, we carried out the survey with the same aforementioned procedure. After a TLS and Photogrammetric acquisition, a session of flights allowed to cover the entire site for post processing. For the orientation of the acquisition, "markers" were used as GCP, their coordinates imported into Photoscan and the model roto-traslated accordingly. In Figure 7, the other two excavated areas subject of this last survey are reported. At this final
Table 2: Synthesis of the orientation residual after the optimization

\begin{tabular}{|l|l|l|l|l|}
\hline & X err $(\mathrm{m})$ & Y err $(\mathrm{m})$ & Z err $(\mathrm{m})$ & Err (Pix) \\
\hline Total Error & 0.008696 & 0.009284 & 0.018750 & 0.293 \\
\hline
\end{tabular}

stage, it is possible to have a complete coverage of the site, even if data are from different data sources and from different periods. The obtained outcomes and the results in terms of accuracy are reported in the following section. A comparison of the outputs from the different sources is reported as well.

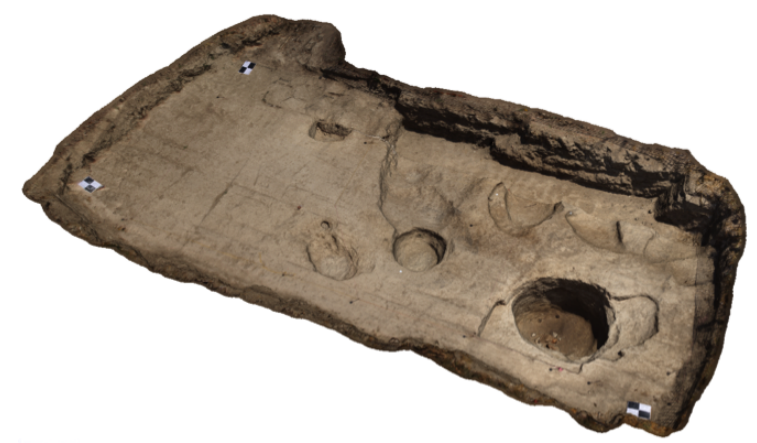

Figure 7: The $3 \mathrm{~d}$ representation of the area recorded during the excavation session in 2015. Note some of the GCP, placed for the orientation of the model

\section{DISCUSSION AND RESULTS}

With all the excavations models oriented into the same reference system, it is now possible to proceed with the creation of orthophotos, and following with the photomosaic of the entire archaeological site. The final result is visible in Figure 8

With respect with the last flight session performed in 2015, the acquisition was made at a flight highness of 29,1 metres, to obtain a GSD of $9.2 \mathrm{~mm} /$ pix. The acquisition was performed with a Sony Powershot S100 with a resolution of 4000 x 3000 pix, a pixel size of $0.006 \mathrm{~mm}$ and a $5.2 \mathrm{~mm}$ focal length. The acquisition consisted in 380 images; the software computed 257.181 tie points, with a reprojection error of 0.498 pix. It is worthwhile to underline that the strong presence of vegetation badly affect the accuracy of the tie points, since it is not stable according to the standing point of the image acquisition. To overcome this problem, the tie points related with the vegetation were manually removed; after performing the bundle adjustment, the final orientation with the GCPs reached the accuracy values reported in Table 2. For completeness, we report the Digital Elevation Model, where is visible the morphology of area excavated in 2015 (9).

To evaluate the different types of data processed and to outline our conclusion over the proposed pipeline of work, we performed a comparison between UAV and TLS dataset, using the latter as test bench. To present our results, we chose the latest dataset, gained during the 2015 campaign. The open software Cloud Compare $^{2}$ was used. In particular, 10 shows that in the flat areas of the site, were the shadows of the vegetation is high and the contrast of the images was not optimal, the average error is comparable to the GSD (about $1 \mathrm{~cm}$ ). Obviously, in the undercutting areas the error increases. Given the above, we can state that, given the validation method performed, for archaeological purposes, digital photogrammetry, also from UAV platforms, is interchangeable with TLS survey The ortophoto obtained resulted an optimal support for the drawing, making the operations faster

\footnotetext{
${ }^{2}$ http://www.danielgm.net/cc/, last access April 16, 2016
} 


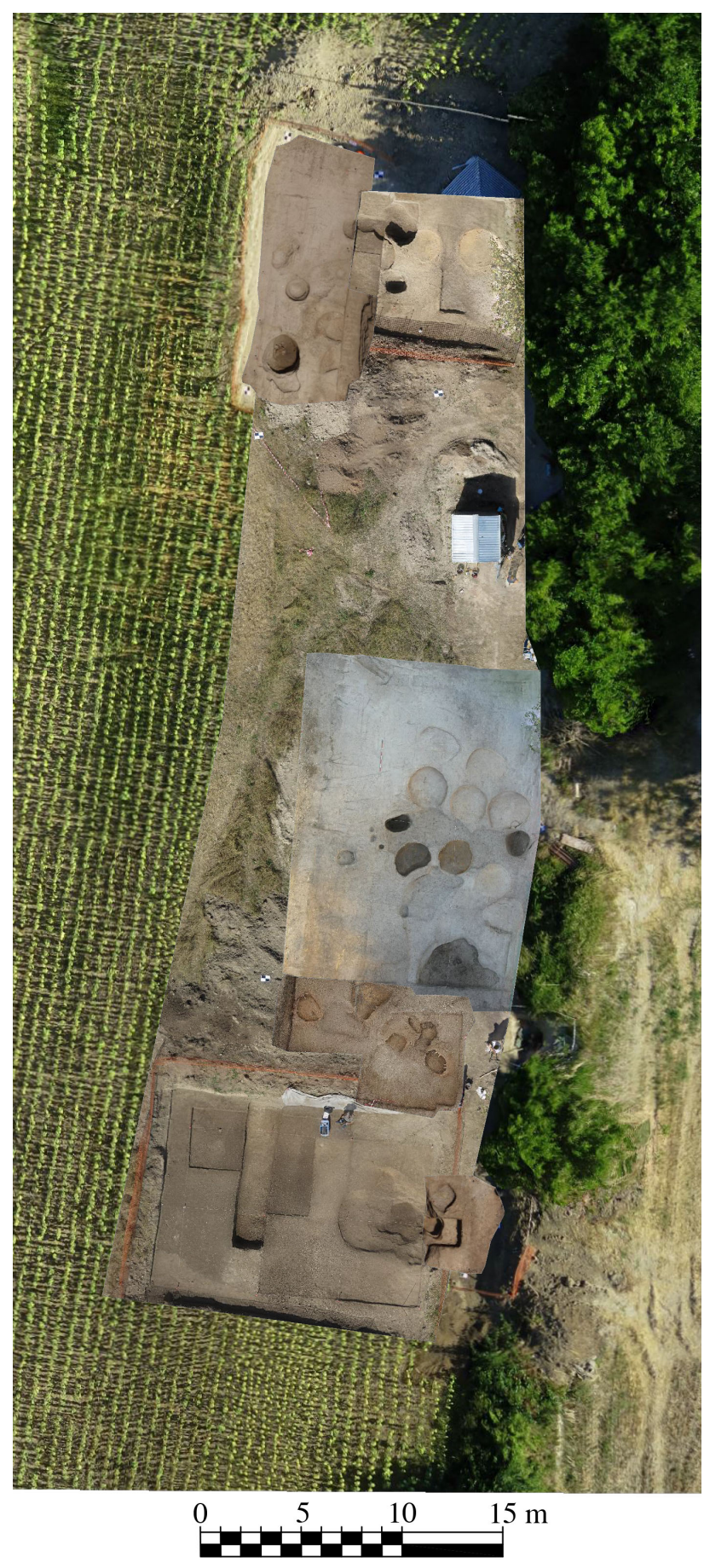

Figure 8: Ortophoto mosaic of the whole site, achieved with the completion survey by UAV

in comparison with the use of the laser scan pointcloud, which has been used as a control of the ortophoto's accuracy.

\section{CONCLUSION AND FUTURE WORKS}

The goal of this work was to test different applications of aerial UAV and CRP surveys for archaeological purposes, combined with TLS survey as control and integration, to represent as completely as possible the entire area. The use of different techniques was fundamental to obtain a complete survey. With respect to photogrammetric surveys, TLS still remains the more ac-

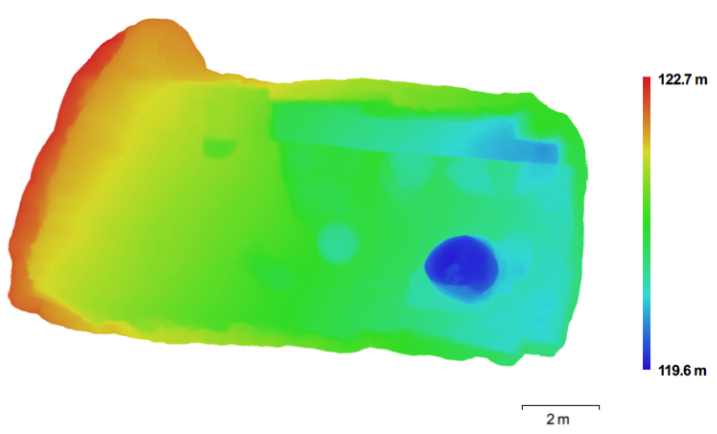

Figure 9: Reconstructed Digital Elevation Model

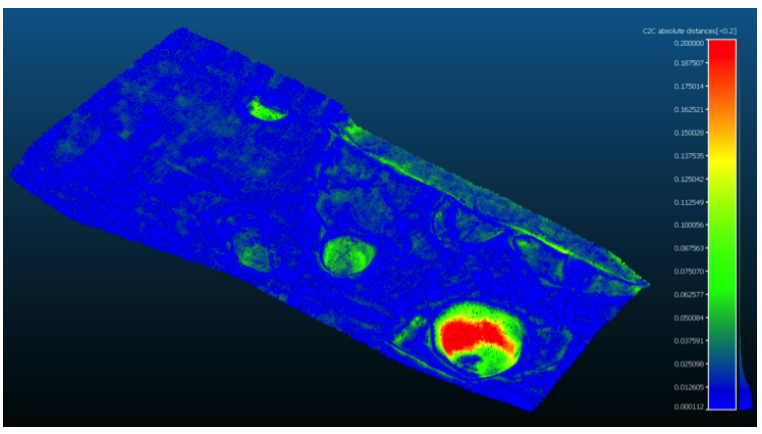

(a)

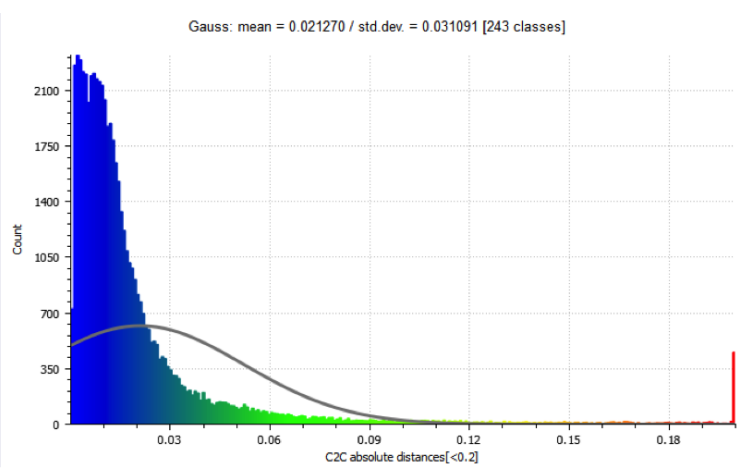

(b)

Figure 10: a) Comparison between the 2 clouds (TLS and UAV) performed with Cloud Compare; b) Cloud-to-cloud distances in Cloud Compare

curate survey method, even if we can consider them interchangeable. In this specific case, the management of the occlusions could be done only through CRP approaches, especially due to the tiny dimensions of the ovens During the years of the excavations, we produces several representations for the studies; to achieve the presented results, an integrated pipeline of work was presented. The topographic network allowed to assemble dataset arising from different period and from different sources in a unique reference system. The adoption of UAV survey was fundamental for the completion of this type of site, which is discovered, excavated and closed after the collection of findings. Thanks to the 3D models and the cartographic representation we gained a complete metrical documentation of the site. DTM, DSM and profiles are useful for in-depth analysis from the archaeologists team. In the future, we are planning to exploit the huge amount of data to built up a virtual experience, allowing the wide public to know about the existence of this unique example of archaeology. The collecting data form the underlying GIS data structure (Conati Barbaro et al., 2013), implementing the spatial extension of the archaeological database, providing 
the possibility of in-depth dimensional and interpretative analysis and helping to ensure cross-disciplinary cooperation in the management and protection of heritage resources (Pierdicca et al., 2015b). With direct link to the geo-database, we foresee to develop Augmented and Virtual Reality (AR) ((Pierdicca et al., 2015a), (Clini et al., 2014)) experiences to allow a quick real time visualization of 3D models and show the way forward smart tourism and virtual museum applications.

\section{REFERENCES}

Balletti, C., Guerra, F., Scocca, V. and Gottardi, C., 2015. 3d integrated methodologies for the documentation and the virtual reconstruction of an archaeological site. The International Archives of Photogrammetry, Remote Sensing and Spatial Information Sciences 40(5), pp. 215.

Barbaro, C. C., 2013. Cooking, working and burying in ancient neolithic: the ovens of portonovo (marche, italy). Origini: Preistoria e protostoria delle civiltà antiche (35), pp. 31-51.

Chiarini, S., Cremonesi, S., Fregonese, L., Fassi, F. and Taffurelli, L., 2014. A multi-range approach for cultural heritage survey: a case study in mantua unesco site. The International Archives of Photogrammetry, Remote Sensing and Spatial Information Sciences 40(5), pp. 157.

Clini, P., Frontoni, E., Quattrini, R. and Pierdicca, R., 2014. Augmented reality experience: From high-resolution acquisition to real time augmented contents. Advances in Multimedia 2014, pp. 18.

Conati Barbaro, C. and Celant, A. .-. O., Rome 5-9 October 2015. Coltivare, conservare, condividere. aspetti economici e sociali della coltivazione dei cereali nel neolitico antico: $i$ dati archeologici e archeobotanici del sito di portonovo (ancona). In: 50th Scientific Meeting of the Italian Institute of Prehistory and Protohistory (IIPP).

Conati Barbaro, C., Malinverni, E. S., Tassetti, A. N. and La Marca, C., 2013. The archaeological excavation of the early neolithic site of portonovo as a case study for testing a $3 \mathrm{~d}$ documentation pipeline. In: Proceedings of the 42nd Annual Conference on Computer Applications and Quantitative Methods in Archaeology, Archeopress, pp. 593-602.

Dellepiane, M., DellUnto, N., Callieri, M., Lindgren, S. and Scopigno, R., 2013. Archeological excavation monitoring using dense stereo matching techniques. Journal of Cultural Heritage 14(3), pp. 201-210.

Guidi, G., Remondino, F., Russo, M., Menna, F. and Rizzi, A., 2008. 3d modeling of large and complex site using multi-sensor integration and multi-resolution data. In: VAST, pp. 85-92.

Lonneville, B., De Roo, B., Stal, C., De Wit, B., De Wulf, A. and De Maeyer, P., 2014. Accurate and cost-efficient 3d modelling using motorized hexacopter, helium balloons and photo modelling: A case study. Lecture Notes in Computer Science (including subseries Lecture Notes in Artificial Intelligence and Lecture Notes in Bioinformatics) 8740, pp. 410-417.

Nilsson, D., 2013. The usage of unmanned aerial vehicles and their prospects in archaeology.

Pierdicca, R., Frontoni, E., Zingaretti, P., Malinverni, E. S., Colosi, F. and Orazi, R., 2015a. Making visible the invisible. augmented reality visualization for $3 \mathrm{~d}$ reconstructions of archaeological sites. In: Augmented and Virtual Reality, Springer, pp. 2537.
Pierdicca, R., Malinverni, E. S., Clini, P., Mancini, A., Bozzi, C. A. and Nespeca, R., 2015b. Development of a gis environment for archaeological multipurpose applications: the fano historic centre. In: XIII International Forum Le Vie dei Mercanti, IEEE Computer Society, pp. 588-597.

Rinaudo, F., Chiabrando, F., Lingua, A. M. and Spanò, A. T., 2012. Archaeological site monitoring: Uav photogrammetry can be an answer. International Archives of the Photogrammetry, Remote Sensing and Spatial Information Sciences 39(B5), pp. 583588.

Sulaiman, N. S., Bachad, E. W., Chong, A. K., Majid, Z. and Setan, H., 2013. Generating three-dimensional photo-realistic model of archaeological monument via multi-sensorsdata integration. International Journal of Research in Engineering and Technology 2(10), pp. 362-373.

Themistocleous, K., Agapiou, A., King, H., King, N. and Hadjimitsis, D., 2014. More than a flight: The extensive contributions of uav flights to archaeological research the case study of curium site in cyprus. Lecture Notes in Computer Science (including subseries Lecture Notes in Artificial Intelligence and Lecture Notes in Bioinformatics) 8740, pp. 396-409.

Uribe, P., Angás, J., Pérez-Cabello, F., de la Riva, J., Bea, M., Serreta, A., Magallón, M. A., Sáenz, C. and Martín-Bueno, M., 2015. Aerial mapping and multi-sensors approaches from remote sensing applied to the roman archaeological heritage. The International Archives of Photogrammetry, Remote Sensing and Spatial Information Sciences 40(5), pp. 461. 